\title{
Measuring Efficiency of Knowledge Production in Health Research Centers Using Data Envelopment Analysis (DEA): A Case Study in Iran
}

\author{
Mohammad Meskarpour Amiri ${ }^{1}$, Taha Nasiri ${ }^{2}$, Seyed Hassan Saadat ${ }^{3}$, Hosein Amini Anabad ${ }^{4}$, Payman Mahboobi \\ $\operatorname{Ardakan}^{5}$
}

\footnotetext{
${ }^{1}$ Health Management Research Center, Baqiyatallah University of Medical Sciences, Tehran, Iran

2 Department of Health Management and Economics, School of Public Health, Tehran University of Medical Sciences, Tehran, Iran

${ }^{3}$ Behavioral Sciences Research Center, Baqiyatallah University of Medical Sciences, Tehran, Iran

${ }^{4}$ Department of Epidemiology, School of Public Health, Iran University of Medical Sciences, Tehran, Iran

${ }^{5}$ Hospital Management Research Center, Shahid Sadoghi University of Medical Sciences, Yazd, Iran
}

\section{Type of article: Original}

\begin{abstract}
Introduction: Efficiency analysis is necessary in order to avoid waste of materials, energy, effort, money, and time during scientific research. Therefore, analyzing efficiency of knowledge production in health areas is necessary, especially for developing and in-transition countries. As the first step in this field, the aim of this study was the analysis of selected health research center efficiency using data envelopment analysis (DEA).

Methods: This retrospective and applied study was conducted in 2015 using input and output data of 16 health research centers affiliated with a health sciences university in Iran during 2010-2014. The technical efficiency of health research centers was evaluated based on three basic data envelopment analysis (DEA) models: inputoriented, output-oriented, and hyperbolic-oriented. The input and output data of each health research center for years 2010-2014 were collected from the Iran Ministry of Health and Medical Education (MOHE) profile and analyzed by R software.

Results: The mean efficiency score in input-oriented, output-oriented, and hyperbolic-oriented models was $0.781,0.671$, and 0.798 , respectively. Based on results of the study, half of the health research centers are operating below full efficiency, and about one-third of them are operating under the average efficiency level. There is also a large gap between health research center efficiency relative to each other.

Conclusion: It is necessary for health research centers to improve their efficiency in knowledge production through better management of available resources. The higher level of efficiency in a significant number of health research centers is achievable through more efficient management of human resources and capital. Further research is needed to measure and follow the efficiency of knowledge production by health research centers around the world and over a period of time.
\end{abstract}

Keywords: Technical efficiency, Data envelopment analysis, Health research centers

\section{Introduction}

Measuring efficiency has been common in a large range of activities, including health care $(1,2)$, insurance services (3), universities $(4,5)$, and research activities (6). Analyzing efficiency through DEA (data envelopment analysis) is an assessment of output-input ratio in order to find relative efficiencies of decision-making units (DMUs) (7). DEA is one of the best approaches for comparative performance assessment (8). DEA is well known as a powerful and also easily understandable analytical tool $(9,10)$. Further, its superiority compared with other techniques has been proven by several studies $(11,12)$. During the last few decades, the health sector has experienced a dramatic growth in cost in developed and developing countries, and inefficiency of health sectors, at least in part, has contributed to

\section{Corresponding author:}

Hosein Amini_Anabad, Department of Epidemiology, School of Public Health, Iran University of Medical Sciences, Tehran, Iran. Tel: +98.2182482420, Fax:+98.2188057022, Email: hmrc1391@gmail.com

Received: February 07, 2016, Accepted: May 03, 2016, Published: November 2016

iThenticate screening: April 20, 2016, English editing: August 14, 2016, Quality control: October 26, 2016

(C) 2016 The Authors. This is an open access article under the terms of the Creative Commons Attribution-NonCommercialNoDerivs License, which permits use and distribution in any medium, provided the original work is properly cited, the use is non-commercial and no modifications or adaptations are made. 
this growth $(13,14)$. In response to this situation, extensive empirical studies have focused on the measurement of efficiency of health institutions around the world. While hospitals are the subject of most of these studies, there are few studies about health research center efficiency. Nowadays, due to the rapid progress of research systems, the regular collection and reporting information about the performance of research centers are common practices. Research center information and reports can provide a general overview about their performance $(15,16)$, and the next logical step is to begin comparison of the efficiency of research centers. Through such comparisons, the most efficient research units can be identified and considered as benchmarks for improving the efficiency and effectiveness of others (17). Iran also has experienced an impressive advance in knowledge production during the past decades $(18,19)$. The numbers of health research centers increased from 53 in 2001 to 359 in 2010 during the last decade. Research centers are growing rapidly in Iran and will continue to provide excellent opportunities in knowledge production (15). Also Iran's government provides great financial support for health research centers and research projects in order to advance knowledge production more progressively $(15,20)$. Therefore, using efficiency analysis is necessary in the area of health knowledge production. Our study is the first step in analyzing efficiency of knowledge production in health areas and can be a good model for analyzing efficiency of knowledge production, especially for developing and in-transition countries. The aim of our study is to measure efficiency of knowledge production by a sample of health research centers using data envelopment analysis. This paper used a comprehensive methodology of data envelopment analysis (DEA) to measure health research center efficiency in Iran.

\section{Material and Methods}

This retrospective and applied study conducted in 2015 used input and output data of 16 health research centers affiliated with a health sciences university during 2010-2014. The 16 research centers included virology, nephrology and urology, nano biotechnology, microbiology, gastroenterology and hepatology, behavioral sciences, neurosciences, human genetics, sports physiology, trauma, molecular biology, biotechnology, nutrition and hygiene, chemical injuries, medicine and religion and health management. The input and output data of the health research centers for years 2010-2014 were collected from the Iran Ministry of Health and Medical Education (MOHE) profile. The input data included the average amount of annual budget, faculty researchers, and staff researchers employed in each health research center during five years (2010-2014). These inputs could well represent labor and capital used in the knowledge production process and have been widely considered in previous studies as the main factors affecting knowledge production in research centers $(20,21)$. The output data included the average number of published papers indexed in ISI web of science, paper citations according to Scopus website report, and the textbooks written by each research center during 2010-2014. These outputs introduced and reported by the Iran Ministry of Health as the main indicators of measuring knowledge production of health research centers. These outputs also have been used in previous studies for measuring knowledge production of research centers $(15,16)$. Using the average five years (2010-2014) of inputs and outputs data was because the result of some research activities appear in the long-run (five year). The three main models of DEA, included input-oriented model, outputoriented model, and hyperbolic-oriented model in the VRS (variable returns to scale) approach, were used to study the relative efficiency of health research centers. The input-oriented model focused on minimizing the resources for a certain level of production, while the output-oriented model focused on maximizing production in a certain level of resources. The hyperbolic-oriented model focused on both resource minimizing and production maximizing simultaneously (22). In DEA models, the efficiency scores 1 means complete efficiency and the efficiency scores smaller than 1 means relatively not complete efficacy. The input and output data of each research center were entered into R software, and the numerical score of each research center's efficiency were calculated and reported.

\section{Results}

The numerical values of each research center's efficiency in three main models, including input-oriented, outputoriented, and hyperbolic, are reported in Table 1. Eight research centers have complete efficiency in all the three models, including chemical injuries, nutrition and hygiene, trauma, human genetic, medicine and religion, gastroenterology and herpetology, microbiology, and virology. Dispersion indexes of efficiency scores in each of the three models are shown in Table 2. The minimum efficiency score in input-, output-, and hyperbolic-oriented models was $0.043,0.048$, and 0.11 , respectively. The applied biotechnology research center have the minimum efficiency level in the input-oriented model with a score of 0.043 and the nano biotechnology research center has a minimum efficiency level in both output-oriented and hyperbolic-oriented models with 0.048 and 0.11 efficiency score, respectively. The mean efficiency score in input-oriented, output-oriented, and hyperbolic-oriented models was $0.781,0.671$, and 0.798 , respectively. In Table 3 , research centers with less than the mean scores reported as an under-average efficiency research center. According to Table 3, seven research centers were below the average 
http://www.ephysician.ir

efficiency in the input-oriented model, and six research centers were below the average efficiency in output- and hyperbolic-oriented models. Five research centers (including applied biotechnology, sports physiology, behavioral sciences, health management, and nano biotechnology) were under the average efficiency in all the three models.

Table 1. Scores of Each Research Center's Efficiency in DEA Models

\begin{tabular}{|l|l|l|l|}
\hline Health Research Center & Input-Oriented & Output-Oriented & Hyperbolic-Oriented \\
\hline Chemical injuries & 1.000 & 1.000 & 1.000 \\
\hline Nutrition and hygiene & 1.000 & 1.000 & 1.000 \\
\hline Applied biotechnology & 0.043 & 0.144 & 0.130 \\
\hline Molecular biology & 0.445 & 0.870 & 0.852 \\
\hline Trauma & 1.000 & 1.000 & 1.000 \\
\hline Human genetic & 1.000 & 1.000 & 1.000 \\
\hline Sports physiology & 0.503 & 0.294 & 0.603 \\
\hline Medicine and religion & 1.000 & 1.000 & 1.000 \\
\hline Neurosciences & 1.000 & 0.148 & 0.880 \\
\hline Behavioral sciences & 0.569 & 0.602 & 0.703 \\
\hline Gastroenterology and hepatology & 1.000 & 1.000 & 1.000 \\
\hline Health management & 0.735 & 0.266 & 0.735 \\
\hline Microbiology & 1.000 & 1.000 & 1.000 \\
\hline Nano biotechnology & 0.449 & 0.048 & 0.110 \\
\hline Nephrology and urology & 0.756 & 0.368 & 0.756 \\
\hline Virology & 1.000 & 1.000 & 1.000 \\
\hline
\end{tabular}

Table 2. Dispersion Indexes of Efficiency Scores in Each DEA Model

\begin{tabular}{|l|l|l|l|l|l|l|}
\hline Method & Min & 1st Qu & Median & Mean & 3rd Qu & Max \\
\hline Input-Oriented & 0.043 & 0.536 & 1.000 & 0.781 & 1.000 & 1.000 \\
\hline Output-Oriented & 0.048 & 0.287 & 0.935 & 0.671 & 1.000 & 1.000 \\
\hline Hyperbolic-Oriented & 0.110 & 0.719 & 0.940 & 0.798 & 1.000 & 1.000 \\
\hline
\end{tabular}

Table 3. Under Average Efficiency Research Centers in Each DEA Model

\begin{tabular}{|l|l|l|}
\hline Input-Oriented & Output-Oriented & Hyperbolic-Oriented \\
\hline Under average efficiency & Under average efficiency & Under average efficiency \\
\hline Applied biotechnology & Applied biotechnology & Applied biotechnology \\
\hline Molecular biology & Sports physiology & Sports physiology \\
\hline Sports physiology & Neurosciences & Behavioral sciences \\
\hline Behavioral sciences & Behavioral sciences & Health management \\
\hline Health management & Health management & Nano biotechnology \\
\hline Nano biotechnology & Nano biotechnology & Nephrology and urology \\
\hline Nephrology and urology & & \\
\hline
\end{tabular}

\section{Discussion}

The considerable advances in health science in the twentieth century have become obvious, and it is really necessary to maintain this capacity for continued scientific advance in the twenty-first century. This goal is not achievable without a greater focus on efficiency of health science researches. Therefore, focusing on the efficiency of a health research center seems to be critical. Improving the efficiency of health research centers can provide a suitable foundation for these crucial health scientific advances. In recent years, the number of health research centers has expanded, which have had a significant role in health knowledge production. Assessing the efficiency of research centers is vital for effective performance and utilization of knowledge production activities, and our study is a first step is this area. The application of DEA can enable health research centers to identify deficiencies and taking appropriate actions for improvement. In this study, the efficiency of health research centers was evaluated based on three basic data envelopment analysis (DEA) models: input-oriented, output-oriented, and hyperbolic-oriented. In the input-oriented model, the mean of efficiency score was 0.781 . It means that, among 16 research centers, seven research centers $(44 \%)$ have been working below average efficiency level and should reduce their inputs for producing the same level of outputs. In the output-oriented model, the mean of efficiency score was 0.67 . This 
means that six research centers $(37 \%)$ have been working under the average efficiency level and should increase their outputs by the same level of outputs, and the average performance can be 0.33 percent better. Based on the hyperbolic-oriented model, the mean of efficiency score was 0.798 . So, according to the results of the model among 16 research centers, six research centers $(37 \%)$ have been working under the average-efficiency level. These research centers should reduce their inputs and increase their outputs simultaneously.

Based on the findings of this study, only $50 \%$ percent of health research centers (eight from 16) were completely efficient. In all the studied models, $31 \%$ of research centers (including applied biotechnology, sports physiology, behavioral sciences, health management, and nano biotechnology) were identified as under-average efficiency research centers. So it is necessary for health research centers to improve their efficiency through better management of available resources. The application of DEA to assess RandD efficiency of 29 universities in China indicated that universities that have improved their management achieved a high efficiency value regardless of whether their original RandD strengths were strong or weak. They expressed that such a measure is proved to be helpful for motivating universities to keep on improving their RandD management (23). Also Agasisti and Haelerman in their study analyzed the performance of public universities in Italy and The Netherlands. According to their findings, the relative efficiency of Italian and Dutch universities is largely dependent on policy adoption. When Italian universities were much more efficient in cost minimizing for a given level of activity, Dutch universities were more efficient in realizing European goals and minimizing resources to obtain a high number of graduates (4).

While many studies have measured the efficiency of hospitals and health service institutions, there are only a few studies on measuring the efficiency of health research centers. In a similar study by Dabagh (24), efficiency and productivity of the research sectors of 31 capital universities of Iran have been investigated using data envelopment analysis (DEA); results showed that most universities (74\%) were technically inefficient in research filed in 2007. In another study by Afonso and Santos (25) on relative efficiency of Portuguese public universities by DEA, output efficiency scores were 0.77, which means that, with the same inputs, the average faculty seems to be obtaining 23 percent-less performance than it should. Also in a study by Kuah and Wong (26) in Malaysia, the efficiency of 30 universities was assessed through DEA in teaching and research activities separately. The results showed that three universities were efficient in their teaching activities and 11 universities were efficient in their research activities. Out of these 30 universities, only one university was efficient in all the criteria. According to the results of our study, a large gap exists between maximum and minimum efficiency scores of different research centers. This has been confirmed by studies conducted in developing and lower income countries. For example, Taylor and Harris (27) showed considerable and time progressive differences in relative efficiency among South African universities. Also in a study by Dabagh (24), the result of five years following efficiency suggests that, despite large differences in relative efficiency of universities in Iran, there has been no significant improvement in research efficiency in these five years. A study of Australian public university efficiency suggests that Australian universities are operating at a fairly high level of efficiency relative to each other (28). However, an empirical study by Zhigang et al. on total factor productivity in China showed that the country's eastern regions were significantly and constantly more efficient than the western regions during the years 1978-2003 (29). Due to the undesirable efficiency level in a large number of health research centers and also due to the large gap between efficiency of health research centers, our study suggests future studies should focus on identify factors affecting efficiency in health research centers. A balanced efficiency improvement is necessary in order to make health science progress more desirable. In order to reach this goal, it is necessary that future studies focus on the institutional and environmental factors affecting health research center efficiency. Also some factors include manager's experience and skills mentioned previously by some studies (30); still there are many unknown factors affecting efficiency of health research centers.

\section{Limitations}

The present study has limitations that we would like to note as follows: first, in our study, we compare research centers together without considering their field of activity. Comparing efficiency of research centers in different field of sciences separately - such as clinical and none clinical research centers - can provide more accurate comparisons. Second, we use only a nonparametric method to measure efficiency of research centers, but using parametric methods also can be useful for such comparisons. Our study was just a first step in analyzing efficiency of knowledge production in health areas, and future studies should be done without such limitations.

\section{Conclusions}

Despite increasing the number of health research centers in recent years and their role in producing knowledge and health promotion in society, based on the results of this study, one-half of the studied research centers are operating 
below full efficiency. Also, a significant number of research centers (one-third) are operating under an average efficiency level, and still there is a large gap between research center efficiency relative to each other. Thus, the higher level of efficiency in a significant number of the health research centers will occur through more efficient management of human resources and capital. Further researches are needed for measuring and following the efficiency of knowledge production by health research centers around the world and over a period of time using DEA techniques. Because many health research centers regard themselves in global competition, international comparisons are also necessary in future studies.

\section{Acknowledgments:}

This research paper is made possible through the help and support from the Deputy of Research and Technology, and all the studied Health Research Centers. First, please allow us to dedicate our acknowledgment of gratitude toward the 17 health research centers' chairman who graciously agreed to participate in our study and volunteered to share with us their research experiences. Second, we should acknowledge the health research centers' staff that made data available to us upon request. Third, we would like to thank Mr. Dopeykar and Mrs. Meddizadeh for reading our work and for providing valuable advice. Finally, we thank Dr. Teymourzadeh for his support and encouragement.

\section{Conflict of Interest:}

There is no conflict of interest to be declared.

Authors' contributions:

All authors contributed to this project and article equally. All authors read and approved the final manuscript.

\section{References:}

1) Rumbold BE, Smith JA, Hurst J, Charlesworth A, Clarke A. Improving productive efficiency in hospitals: findings from a review of the international evidence. Health Econ Policy Law. 2015; 10(1): 21-43. doi: 10.1017/S174413311400022X. PMID: 25662195.

2) Di Giorgio L, Flaxman AD, Moses MW, Fullman N, Hanlon M, Conner R, et al. Efficiency of Health Care Production in Low-Resource Settings: A Monte-Carlo Simulation to Compare the Performance of Data Envelopment Analysis, Stochastic Distance Functions, and an Ensemble Model. PLoS One. 2016; 11(1). doi: 10.1371/journal.pone.0147261.

3) Knezevic S, Markovic M, Brown A. Measuring the efficiency of Serbian insurance companies. Acta Oeconomica. 2015; 65(1): 91-105. doi: 10.1556/AOecon.65.2015.15.

4) Agasisti $T$, Haelermans C. Comparing efficiency of public universities among European countries: Different incentives lead to different performances. Higher Education Quarterly. 2015; 70(1): 81-104. doi: 10.1111/hequ.12066.

5) Kyratzi P, Tsamadias C, Giokas D. Measuring the efficiency and productivity change of Greek universities over the time period 2005-2009. Int J of Education Economics and Development. 2015; 6(2): 111-29. doi: 10.1504/IJEED.2015.070620.

6) You ZQ, Han XP, Hadzibeganovic T. The role of research efficiency in the evolution of scientific productivity and impact: An agent-based model. Physics Letters A. 2015; 380(7): 828-36. doi: 10.1016/j.physleta.2015.12.022.

7) Belu C. Are distance measures effective at measuring efficiency? DEA meets the vintage model. J Prod Anal. 2015; 43(3): 237-48. doi: 10.1007/s11123-015-0438-y.

8) Du J, Zhu J, Cook WD, Huo. DEA Models for Parallel Systems: Game-Theoretic Approaches. Asia Pac J Oper Res. 2015; 32(02): 155-77. doi: 10.1142/S0217595915500086.

9) Lee HS, Zhu J. Super-efficiency infeasibility and zero data in DEA. Euro J Oper Res. 2012; 216(2): 42933. doi: 10.1016/j.ejor.2011.07.050.

10) Kadarova J, Durkacova M, Teplicka K, Kadar G. The Proposal of an Innovative Integrated BSC-DEA Model. Procedia Economics and Finance. 2015; 23(1): 1503-8. doi: 10.1016/S2212-5671(15)00375-5.

11) Wu DD, Yang $Z$, Liang L. Using DEA-neural network approach to evaluate branch efficiency of a large Canadian bank. Exp sys appl. 2006; 31(1): 108-15. doi: 10.1016/j.eswa.2005.09.034.

12) Velasquez M, Hester PT. An analysis of multi-criteria decision making methods. Int J Oper Res. 2013; 10(2): 56-66. doi: 10.1.1.402.1308. 
13) Carter R, Vos T, Moodie M, Haby M, Magnus A, Mihalopoulos C. Priority setting in health: origins, description and application of the Australian Assessing Cost-Effectiveness initiative. Expert Rev Pharmacoecon Outcomes Res. 2014; 8(6): 593-617. doi: 10.1586/14737167.8.6.593.

14) Keehan SP, Cuckler GA, Sisko AM, Madison AJ, Smith SD, Stone DA, et al. National health expenditure projections, 2014-24: spending growth faster than recent trends. Health Aff. 2015; 34(8): 1407-17. doi: 10.1377/hlthaff.2015.0600.

15) Falahat K, Eftekhari M, Habibi E, Djalalinia Sh, Peykari N, Owlia P, et al. Trend of Knowledge Production of Research Centers in the Field of Medical Sciences in Iran. Iran J Public Health. 2013; 42(1): 55. PMID: 23865017, PMCID: PMC3712585.

16) Welter F, Schroder S, Leisten I, Richert A, Jeschke S. Scientific Performance Indicators-empirical results from collaborative research centers and clusters of excellence in Germany. IRSPM 16th. Annual congress. 2014; 203-20. doi: 10.1007/978-3-319-08816-7-17.

17) Zhu J. Quantitative models for performance evaluation and benchmarking: data envelopment analysis with spreadsheets. 2014, 1th edition, New York, 297. doi: 10.1007/978-3-319-06647-9.

18) Sabouri AA. Iranian Science Production in 2010. Quarterly Journal of Scientific Transplanting. 2011; 1(2): $16-23$.

19) Ghojazadeh M, Naghavi-Behzad M, Nasrolah-Zadeh R, Bayat-Khajeh P, Piri R, Mirnia K, et al. Knowledge production status of Iranian researchers in the gastric cancer area: based on the medline database. Asian Pac J Cancer Prev. 2014; 15(12): 5083-8. doi: 10.7314/APJCP.2014.15.12.5083. PMID: 24998590.

20) Yaghoubi Farani A, Shariati MT. Factors affecting research center's performance: The case of research centers of former of former ministry of Jihad-E-Sazanbegi. Ianian Agricultural Extension and Education Journal. 2008; 3(2): 1-13.

21) Yadollahi M, Shamseddini N, Shayan L, Rezaianzadeh A, Bolandparvaz Sh. The Performance of Trauma Research Centers of Iran during the Past 10 Years: A Science Monitor Survey. Bullettn Of Emergency and Trauma Beat. 2014; 2(1): 44-51.

22) Azar A, Torkashvand AR. Assessing the teaching researching performance with the help of data envelopment analysis model: teaching groups of humanity sciences faculty. Mod Hum Sci. 2006; 10(1): 123.

23) Feng YJ, Lu H, Bi K. An AHP/DEA method for measurement of the efficiency of R\&D management activities in universities. Int Trans Oper Res. 2004; 11(2): 181-91. doi: 10.1111/j.1475-3995.2004.00450.x.

24) Dabbagh R. The comparison of research and total productivity of Iranian public universities. Iranian Economic Research. 2011; 16(47): 75-104.

25) Afonso A, Santos M. A DEA approach to the relative efficiency of Portuguese public universities. Portu J Manag St. 2008; 13(1): 67-87. doi: 10.2139/ssrn.744464.

26) Kuah CT, Wong KY. Efficiency assessment of universities through data envelopment analysis. Procedia Computer Sci. 2011; 3: 499-506. doi: 10.1016/j.procs.2010.12.084.

27) Taylor B, Harris G. Relative efficiency among South African universities: A data envelopment analysis. Hig Edu. 2004; 47(1): 73-89. doi: 10.1023/B:HIGH.0000009805.98400.

28) Abbott M, Doucouliagos C. The efficiency of Australian universities: a data envelopment analysis. Eco Edu Rev. 2003; 22(1): 89-97. doi: 10.1016/S0272-7757(01)00068-1.

29) Zhigang G, Liutang C, Yuyu W. China's Regional Differences in Technical Efficiency and the Decomposition of Total Factor Productivity Growth (1978 - 2003). Soc Sci Chin. 2006; 2(1): 1-25.

30) Azizinejad B, Pourheydari R. Factors Affecting Efficiency of Managers of Urumia Medical Sciences University with Emphasis on Triple Management Skills. J Urm Nur Mid Fac. 2014; 12(7): 576-84. 